\title{
LAYOUT OF REST AREAS AND THEIR INFRASTRUCTURE DEVELOPMENT IN THE SOUTH-EASTERN REGION OF LITHUANIA
}

\section{JUSTINA KOLODINSKAJA ${ }^{1 *}$, LINA BERTULIENE ${ }^{2}$ \\ ${ }^{1}$ Vilnius District Municipality, Vilnius, Lithuania \\ ${ }^{2}$ Dept of Roads, Vilnius Gediminas Technical University, Vilnius, Lithuania}

Received 17 February 2020; accepted 19 May 2020

\begin{abstract}
The quality of rest areas is important to every driver and passenger for as much as safety, convenience and functionality need to be ensured. Most often fatigue and lack of sleep become the main reasons of painful accidents; thus, an efficient layout of rest areas encourages drivers to take a rest from intensive driving. National normative documents enforcing the layout of rest areas in Lithuania have been analysed and expertise of foreign countries has been examined in order to understand the planning principles of rest areas in Lithuania and to identify the key problems. Analysis of the existing situation of rest areas in the south-eastern region of Lithuania has been made for the purposes of using adequate methods leading to the increased efficiency of the layout of rest zones. Moreover, a multiple criteria assessment method along with expert opinion compatibility assessment has been used to identify the quality criteria for the selection of rest areas. Upon resolving the optimisation method coverage task, the demand of rest areas and their arrangement principles on the roads in question have been identified. Optimal layout of rest areas has been
\end{abstract}

* Corresponding author. E-mail: justina.kolodinskaja@gmail.com

Justina KOLODINSKAJA (ORCID ID 0000-0002-3837-0686)

Lina BERTULIENE (ORCID ID 0000-0001-8435-1729)

Copyright (C) 2020 The Author(s). Published by RTU Press

This is an Open Access article distributed under the terms of the Creative Commons Attribution License (http://creativecommons.org/licenses/by/4.0/), which permits unrestricted use,

distribution, and reproduction in any medium, provided the original author and source are credited. 
proposed relying on the worldwide experience and provisions of normative documents and guidelines.

Keywords: expert evaluation, layout of rest areas, optimisation, rest area, safety, south-eastern region of Lithuania.

\section{Introduction}

Travelling by car is the most widely spread mode of travelling all over the world. For this reason, the road infrastructure needs to be adequately developed, i.e., it has to be equipped with roadside rest areas, petrol stations, bus stops, tourism information boards, road information and service supply signs, and other infrastructure elements along the road. Roadside infrastructure and distance between these areas shall provide convenient and safe travelling for all road users (Gates, Savolainen, Datta, \& Todd, 2013; McArthur, Kay, Savolainen, \& Gates, 2013). Positioning of the proposed service facilities along the road should be taken into due account to ensure comfort for drivers. The research (Jung, Joo, \& Oh, 2016) showed that the supplemental rest areas reduced freeway crashes caused by drowsy driving by $14 \%$. The supplemental rest areas were most effective in reducing drowsy driving related crashes particularly in freeway sections with 2 or 3 traffic lanes or ramps. The results of the first data-driven study evaluating the effects of these supplemental rest areas imply that supplemental rest areas provide more opportunities to avoid drowsy driving and, therefore, they should be encouraged for freeways as cost-effective safety improvement facilities.

The rest area is the area where car parking zones are separated from the driveway and where drivers and passengers can stop for a short while to rest and have a snack. Rest areas with cafes, petrol stations and food outlets are the most frequented places. A majority of visitors are attracted by the rest areas situated next to picturesque landscapes or natural monuments. Tidy and well-attended rest areas invite to civilized and active leisure or weekend trips. The quality of rest area is very important to every driver or passenger as it influences formation of the local image and attraction of tourists. Furthermore, proper positioning of rest areas has a positive impact on traffic safety organisation on motorways. Emergency situations or traffic accidents do happen even on the roads of moderate traffic flows. Most often fatigue and lack of sleep become the main reasons of painful accidents; thus, efficient positioning of rest areas encourages drivers to take at least a short stop and take a rest from intensive driving.
Layout of Rest Areas and Their Infrastructure Development in the South-Eastern Region of Lithuania 
Rest areas can be grouped into those of long and short rest. Three function zones are typical of a short rest area: car parking zone with an entry and exit points; passenger rest zone with a shelter, tables and benches; sanitary and hygiene zone with waste containers. Long rest areas need to be equipped with service supply complexes.

Economic assessment of construction and upgrading of rest areas for heavy duty vehicles performed in the central part of Queensland State has resulted in a decision to divide areas into 3 categories: the large rest area (intended for longer rest breaks and equipped with 15 or more parking lots); the small rest area (for shorter rest breaks and up to 15 parking lots) and heavy duty vehicle parking area (for short stops, up to 4 parking lots) (Campbell, 2014).

Classification types of the rest areas situated along the roads of Australia are usually as follows:

- Type A. The rest zone like this is abundant in amenities adapted for all types of drivers;

- Type B. Rest zones are intended for short and medium duration rest;

- Type C. Rest zones have a sufficient number of parking lots, which are safely arranged at a proper distance from the motorway (Department of Transport and Main Roads, 2014).

A lot of attention in the US is given to the design and maintenance of rest spaces. It has been identified that an ideal size of rest area makes 20-30 acres ( 10 acres account for a minimal area). The rest area should be quadrangle-shaped with an attractive arrangement of facilities inside it. $50 \mathrm{~km}, 80 \mathrm{~km}, 100 \mathrm{~km}, 150 \mathrm{~km}$ and $300 \mathrm{~km}$ intervals are proposed for planning the positioning of rest zones. It has also been stated by other users of rest areas that an optimal distance between the rest areas should be based on a two-hour driving span (Ministry of Transportation and Infrastructure, 2016).

A usual distance between the main rest areas in Australia makes approximately $100 \mathrm{~km}$, small rest areas are at some $50 \mathrm{~km}$ distance from each other and rest areas for heavy duty vehicles are situated at $30 \mathrm{~km}$ distance from one another (Campbell, 2014). Based on the Australian standards, placing of advance warning signs is preferable to inform about the layout of rest areas along the road: at a distance of $10 \mathrm{~km}$ to the rest area the type of rest area is indicated; $2 \mathrm{~km}$ - type of the rest area and distance to another rest area is stated; $1 \mathrm{~km}$ - an approaching rest area is indicated (Department of Transport and Main Roads, 2014).

Regulations in Spain about the rest areas give no indications about maximum or minimum distances between them and the minimum facilities they must provide. Only a document from 1994 recommends a distance of 40-60 km between successive service areas (Romo-Martína 
\& Pérez-Aceboa, 2018). The maximum distances between areas are based on recommendations from other countries, and, hence, a limit is recommended to improve road safety in Poland (Pérez-Acebo \& RomoMartín, 2019).

The size of rest areas, infrastructure facilities and their purpose are different; thus, they are designed individually for each particular location. A rest area should not be formed as a large and open territory since the concept like this would barely seem attractive or safe to travellers.

A major part of the interviewed Queensland drivers stated that they stopped to rest every $142 \mathrm{~km}$. A priority list of the available facilities in the rest areas given by the drivers was the following: toilets (99.5\%); sufficient space in the rest zone (96\%); a shelter/shed (93\%); a table, chairs and benches (93\%); access to water (89\%) (Department of Transport and Main Roads, 2014).

The German normative standard (Forschungsgesellschaft für Straßen- und Verkehrswesen, 2011) indicates that the aspects listed below should be considered in the planning of rest areas: demand of car parking areas and supply/availability of the proposed sanitary services; top quality conditions to have a rest; safe entry and exit spaces while driving at a high speed; undisturbed car parking and pedestrian traffic; the least possible adverse impact on the nature, landscape and vicinities; investments, operation and maintenance costs.

Safety is the criterion which would stimulate drivers to rely on the infrastructure of rest areas. The main problem in Germany pertaining to rest areas is night robberies. Most attacks have been documented in rest areas near Cologne and highways A3, A8, and A9 between Wurzburg, Munich and Salzburg. Lack of illumination in the rest areas in Germany lead to another problem: after turning from the illuminated highway to the darkness, the car drivers fail to notice an obstacle at the entrance to the rest area and hit the standing long vehicles the drivers of which are taking a rest. In one year, 69 similar traffic accidents were reported in North Rhine-Westphalia alone.

Consistent positioning of rest areas within proportional and logical intervals should be provided for the needs of road users in order to make them feel free and independent from the roadside infrastructure. Newly designed rest zones with service infrastructure should be built at $50-60 \mathrm{~km}$ distance between them or up to $80 \mathrm{~km}$ distance in exceptional cases. Within 15-20 km distance from rest areas with service supply, the rest areas without service supply are equipped. In exceptional cases, where traffic is highly intensive, the above distance is increased to some 25 km (Forschungsgesellschaft für Straßen- und Verkehrswesen, 2011). 
For operational and economic reasons, the rest areas with and without service supply are planned on both sides of the motorway, immediately or nearly immediately in front of one another. Where possible, rest areas with service facilities shall be alternately arranged on the opposite sides of the motorway (Forschungsgesellschaft für Straßen- und Verkehrswesen, 2011).

Based on the expertise and best available practice of the EU member states, the following criteria shall be taken into account when planning locations for the layout of the rest areas: significance of a motorway concerned; traffic safety; design speed on the motorway and traffic volume; number and category of visitors; number and type of vehicles; intended number of parking lots; average duration of vehicle parking; cost-effectiveness; environmental protection; reason of visiting; exceptionality of landscape (Forschungsgesellschaft für Straßen- und Verkehrswesen, 2011).

According to the German normative standard (Forschungsgesellschaft für Straßen- und Verkehrswesen, 2011), rest areas are divided into the following zones: a zone intended for traffic, a zone of passenger and vehicle service facilities, hygiene and sanitary zone, and green plantation zone.

Rest areas should attract as much people as possible provided they are functional, tidy and suggest proper quality of rest due to their safe surroundings.

\section{Rest areas in Lithuania}

Based on the database of the Lithuanian road information system (LAKIS, 2019), the presence of 1143 rest areas and stopping places was reported in Lithuania in 2019. They are grouped according to their type as follows: 263 areas are intended for rest, 372 areas - for stopping, and 508 petrol stations which are distinguished as a separate group.

Activities of logistics, transit roads and road infrastructure turn to become more and more significant in terms of cultural, economic and social aspects on the local and global level (Commission of the European Communities, 2009). In order to deal with the problems encountered, implementation of a joint project Concept of Traffic Safety Improvement in Latvian - Lithuanian Cross-Border Region (2013) has been undertaken by the Transport Development and Education Association of Latvia, Kaunas University of Technology (Lithuania) and the Lithuanian National Association of Forwarders and Logistics. The international project has resulted in the elaboration of technical measures and methodologies for 
No official document on the design, establishment and positioning of rest areas along the Lithuanian motorways is currently available. For this reason, Road Technical Regulation KTR 1.01:2008 (Ministry of Environment of the Republic of Lithuania, 2008), Motorways, is applied. It contains requirements for the establishment and maintenance of rest areas. The number of parking lots in the area is determined according to the forecasted demand and car/vehicle parking zones need to be separated from the driveway. Grade I, II and III rest areas and car/ vehicle parking areas are established at the main and national roads, while regional and local roads are equipped with the rest areas only if their necessity is justified. Rest areas shall be established based on their distance to higher grade areas and positioning of sightseeing places (Ministry of Environment of the Republic of Lithuania, 2008).

Maintenance of rest areas and vehicle parking areas is carried out according to the indices and requirements set in Standards on Regular Maintenance of Motor Roads KVP PN-19 (Lithuanian Road Administration, 2019) based on road maintenance levels (levels I-V).

Upon examination of the Lithuanian normative documents, it has been concluded that the information stated therein is insufficient for planning of the roadside rest areas. There are abundant requirements for the arrangement of car parking lots; however, details for the principles of selection, purpose and arrangement/positioning of roadside rest areas are missing. This causes a problem since the needs of all drivers related to the layout of rest areas are unsatisfied.

\section{Analysis and assessment of the existing situation in the rest areas of the south-eastern region of Lithuania}

Favourable geographic position of Lithuania determines an intensive traffic of heavy-duty vehicles along the roads. The border of Lithuania is crossed by a large number of transit vehicles travelling from the Baltic and Scandinavian countries to Belarus and from South-Eastern Europe via Belarus to Lithuania and other Baltic States. Here, the movement of import and export flows is reported, which leads to a high traffic volume. Both car drivers and heavy-duty vehicle drivers carrying a variety of freight need regular breaks. They have to take a rest from intensive driving, use WC, have a snack, make a visual inspection of the vehicle they drive, and the like. In addition, heavy-duty truck drivers must 
obey the specified driving schedule (to make regular breaks and rest at night). For this reason, the roadside stopping places and rest areas are established in order to make use of the necessary services.

No statistical data on the rest areas of the region in question are available and there is no information on the services provided by them or a number of travellers visiting them, the condition of rest areas, etc. Nevertheless, one may state the presence of a rapid and gradual improvement of the condition of rest areas on a yearly basis. Yet, the main problem of scarce financing of rest area maintenance remains unsolved. As a result of the aforementioned aspects, the development of rest areas and stopping places is extremely relevant; thus, allocation of extra funds for their infrastructure development would be expedient.

Taking into consideration the annual average daily traffic, the main transit roads in South-Eastern Lithuania have been chosen for the research purposes -3 main roads and 2 national roads: A3 VilniusMinsk (3 rest and stopping areas); A4 Vilnius-Varèna-Grodno (13 rest and stopping areas); A15 Vilnius-Lida (6 rest and stopping areas); No. 103 Vilnius-Polock (1 rest and stopping area); No. 127 BabriškèsVarèna-Eišiškès (4 rest and stopping areas).

Table 1. Data on the rest areas and stopping places along the main road A3 (compiled by the authors, 2018)

\begin{tabular}{|c|c|c|c|c|c|c|}
\hline No. & $\begin{array}{c}\text { Location, } \\
\text { km }\end{array}$ & $\begin{array}{l}\text { Area } \\
\text { type }\end{array}$ & $\begin{array}{l}\text { Road } \\
\text { pavement } \\
\text { type }\end{array}$ & $\begin{array}{l}\text { Road } \\
\text { side }\end{array}$ & $\begin{array}{l}\text { Maintenance } \\
\text { company }\end{array}$ & Services supplied \\
\hline 1. & 7.4 & Stopping & $\begin{array}{c}\text { Black } \\
\text { pavement }\end{array}$ & $\begin{array}{l}\text { On the } \\
\text { left }\end{array}$ & Vilnius Unit & $\begin{array}{r}\text { Table for picnics with benches, } \\
\text { recycle bin, sidewalk, road } \\
\text { information signs about the } \\
\text { services }\end{array}$ \\
\hline 2. & 7.593 & $\begin{array}{l}\text { Petrol } \\
\text { station }\end{array}$ & Asphalt & $\begin{array}{l}\text { On the } \\
\text { right }\end{array}$ & Other & $\begin{array}{r}\text { Petrol station " } x x x^{\prime} \text {, catering, } \\
\text { WC, vehicle maintenance (repair } \\
\text { garage), guarded parking site, } \\
\text { road information signs about } \\
\text { services, waste containers, } \\
\text { fencing, illumination }\end{array}$ \\
\hline 3. & 32.451 & $\begin{array}{l}\text { Petrol } \\
\text { station }\end{array}$ & Asphalt & $\begin{array}{c}\text { On the } \\
\text { left }\end{array}$ & Other & $\begin{array}{r}\text { Filling station "xxx", catering, } \\
\text { WC, guarded parking site, tables } \\
\text { for picnics, shelter/shed, bench, } \\
\text { recycle bin, road information } \\
\text { signs about services, waste } \\
\text { containers, fencing }\end{array}$ \\
\hline
\end{tabular}


Information system containing data on the roads of national Infrastructure significance of Lithuania divides the areas into three groups: petrol stations, rest areas and stopping areas. Stopping area No. 1 on the main road A3 is maintained by Vilnius Unit, while the remaining rest areas are taken care by private legal or physical entities. Information on the pavement of rest areas, type and services supplied, etc. is given in Table 1.

The performed analysis of the existing situation of the surveyed roadside rest areas revealed poor condition and the need for constant maintenance of infrastructure facilities and structures in most of the rest areas. Gravel pavement is still found in the rest area on the main road A15. Furthermore, the quality and condition of asphalt pavement in some rest areas are still poor. In most areas the illumination, fencing, WCs, rest zones, parking lots for heavy-duty vehicles and cars, and parking lots with easy access for the handicapped are insufficient or unavailable. The newly built or upgraded rest areas situated at the picturesque surroundings are abundant on the main road A4 VilniusVarèna-Grodno. The use of the best available techniques of foreign countries has been started in Lithuania by dividing the rest areas into function zones; however, the number of rest zones designed this way is still scarce.

\section{Expert opinion compatibility assessment method and the derived results}

Rest area quality is of utmost importance to any driver or passenger. Also, it makes influence on the image formation of the location and on tourist attraction. Quantitative opinion assessment and the outcome processing have been undertaken to identify the key aspects determining the attractiveness of rest areas and prompting the drivers to efficiently visit them.

Quantitative multiple criteria methods or MCDM (Multiple Criteria Decision Making) methods are helpful for deriving the best alternative among the compared alternatives or for ranking them on the basis of their significance in terms of the purpose of assessment. Most of the currently known and applied multiple criteria methods are based on expert evaluations (Podviezko \& Podviezko, 2014; Sivilevičius, 2011).

Expert individual assessment method has been chosen for the survey.

Ten main criteria, which are the most important in prompting the drivers to stop and spend time in a particular rest area, have been selected: safety of rest areas and stopping places; convenience of rest 
areas (infrastructure layout); quality of services supplied in the rest areas and stopping places; distance between the rest areas and stopping places; pavement and pavement condition of the rest areas and stopping places; diversity and development of services proposed by the rest areas; a possibility of overnight stays in the rest area; uniqueness of the landscape proposed by the rest areas and stopping places; information signs indicating the availability of a nearby rest area; accessibility of parking lots in rest areas and stopping places.

The experts (respondents) were selected, i.e., drivers visiting the rest areas, road designers, employees of logistic companies and other experts of the study area, also the car drivers, heavy-duty vehicle drivers and other rest area users who travel for tourism or leisure purposes.

Experts $\mathrm{E}_{1}, \mathrm{E}_{2}, \ldots, \mathrm{E}_{n}$ were handed in a questionnaire and asked to assign qualitative significance estimates, i.e., scores/points to quality criteria $\mathrm{A}, \mathrm{B}, \ldots . \mathrm{J}$. The more significant the index, the higher score is assigned to it: the highest significance is expressed by 10 and the lowest significance - by 1 .

The average rank of each criterion (the mean of ranks) is calculated based on Eq. (1):

$$
\overline{X_{j}}=\frac{\sum_{i=1}^{m} x_{i j}}{m}, j=1, \ldots, n,
$$

where $x_{i j}$ - a score/point assigned by the $i$-th expert to the $j$-th index (criterion); $m$ - a number of experts.

Reliability of expertise can be expressed by expert opinion concordance rate $W$, which indicates a degree of similarity of individual opinions. The higher $W$, the stronger correlation of variables. The more agreement in the expert opinion, the higher degree of value and reliability of the assessment data. Agreement of opinions is calculated based on the value of concordance rate $W$ when no similar ranks are present in the ranking:

$$
W=\frac{12 S_{k}}{m^{2}\left(n^{3}-n\right)},
$$

where $S_{k}$ - the sum of squares of score deviations from the mean; $n-$ a number of ranks (criteria).

The sum of squares of rank deviations from the mean $S_{k}$ indicates the extent of difference of expert evaluations from the overall mean evaluation:

$$
S_{k}=\sum_{j=1}^{n}\left[\sum_{j=1}^{m} x_{i, j}-\frac{1}{2} m(n+1)\right]^{2},
$$

where $m$ - a number of experts; $n$ - a number of ranks (criteria). 
The concordance rate calculated according to Eq. (2) is a random value and its significance of actual concordance is determined according to the following formula:

$$
\chi^{2}=\frac{12 S_{k}}{m n(n+1)}
$$

where $S_{k}$ - the sum of squares of score deviations from the mean; $m$ - a number of experts; $n$ - a number of ranks (criteria).

The value $m W(n-1)$ is distributed according to $\chi^{2}$ law, where a number of freedom degrees $v=n-1$. In case $\chi^{2}$ value derived from the formula exceeds the critical value $\chi_{k r}^{2}$, which depends on quantile $(t=0.95 \ldots 0.99)$ assumed by freedom degrees $v=n-1$, the hypothesis of compatibility of expert opinions is accepted.

Significance (weight) of quality criteria is determined on the basis of methodology (Sivilevičius, 2011). The following formula is used for this purpose:

$$
Q_{j}=\frac{(n+1)-\overline{X_{j}}}{\sum_{i=1}^{m} \overline{X_{j}}}
$$

where $n$ - a number of ranks (criteria); $\overline{X_{j}}$ - a mean rank.

Stability of significance scores of every individual $j$ criterion is assessed in terms of the size of mean square deviation calculated by the Eq. (6):

$$
\sigma_{j}=\sqrt{\frac{\sum_{i=1}^{m}\left(x_{i j}-\overline{X_{j}}\right)^{2}}{m-1}},
$$

where $x_{i j}-i$-th expert-given score to $j$-th index (criteria); $m$ - a number of experts; $\overline{X_{j}}$ - a mean rank.

In this way, the stability of the score of significance for each criterion is determined.

Upon making calculations of expert opinion compatibility evaluation methods, the results of every criterion rate were obtained (they are given in Table 2).

The calculated concordance rate $W=0.45<0.5$; therefore, it could be stated that the opinions of respondents were rather different (incompatible).
Infrastructure

Development in 


\begin{tabular}{|c|c|c|c|c|c|c|c|c|c|c|c|}
\hline \multirow{2}{*}{$\begin{array}{c}\text { Expert } \\
\text { (respondent) } \\
\text { code }\end{array}$} & \multicolumn{10}{|c|}{ Criterion (index) mark } & \multirow[b]{2}{*}{ Sum } \\
\hline & A & B & C & D & $\mathbf{E}$ & $\mathbf{F}$ & $\mathbf{G}$ & $\mathbf{H}$ & $\mathbf{I}$ & $J$ & \\
\hline$E_{1}$ & 2 & 6 & 7 & 1 & 8 & 10 & 3 & 9 & 4 & 5 & 55 \\
\hline$E_{2}$ & 8 & 9 & 3 & 5 & 6 & 4 & 1 & 2 & 7 & 10 & 55 \\
\hline$E_{3}$ & 10 & 5 & 8 & 2 & 3 & 9 & 7 & 1 & 4 & 6 & 55 \\
\hline $\mathrm{E}_{4}$ & 10 & 7 & 6 & 4 & 3 & 2 & 9 & 1 & 5 & 8 & 55 \\
\hline$E_{5}$ & 9 & 10 & 8 & 4 & 3 & 5 & 1 & 2 & 7 & 6 & 55 \\
\hline$E_{6}$ & 6 & 7 & 10 & 2 & 4 & 9 & 1 & 3 & 5 & 8 & 55 \\
\hline$E_{7}$ & 10 & 8 & 9 & 6 & 1 & 7 & 5 & 2 & 3 & 4 & 55 \\
\hline$E_{8}$ & 10 & 8 & 6 & 5 & 7 & 4 & 3 & 2 & 1 & 9 & 55 \\
\hline $\mathrm{E}_{9}$ & 9 & 8 & 10 & 4 & 7 & 5 & 1 & 2 & 3 & 6 & 55 \\
\hline$E_{10}$ & 9 & 8 & 10 & 5 & 4 & 2 & 3 & 1 & 6 & 7 & 55 \\
\hline $\begin{array}{l}\text { Sum of ranks } \\
\sum_{i=1}^{m} x_{i j}\end{array}$ & 83 & 76 & 77 & 38 & 46 & 57 & 34 & 25 & 45 & 69 & 550 \\
\hline Mean rank $\overline{X_{j}}$ & 8.3 & 7.6 & 7.7 & 3.8 & 4.6 & 5.7 & 3.4 & 2.5 & 4.5 & 6.9 & 55 \\
\hline Criteria ranking & 10 & 8 & 9 & 3 & 5 & 6 & 2 & 1 & 4 & 7 & - \\
\hline $\begin{array}{l}S_{k} \text { the sum } \\
\text { of squares of } \\
\text { deviations from } \\
\text { the mean }\end{array}$ & 784 & 441 & 484 & 289 & 81 & 4 & 441 & 900 & 100 & 196 & 3720 \\
\hline $\begin{array}{l}\text { Significance of } \\
\text { criteria } Q_{j}\end{array}$ & 0.049 & 0.062 & 0.060 & 0.131 & 0.116 & 0.096 & 0.138 & 0.155 & 0.118 & 0.075 & 1.0 \\
\hline $\begin{array}{c}\text { Mean square } \\
\text { deviation } \sigma_{j}\end{array}$ & 2.54 & 1.43 & 2.26 & 1.62 & 2.27 & 2.91 & 2.80 & 2.37 & 1.90 & 1.85 & - \\
\hline
\end{tabular}

Opinions of all experts regarding the significance of quality criteria of rest areas coincide, as the calculated critical value $\chi_{k r}^{2}$ equals 21.666 , i.e., it is lower than the calculated value $\chi^{2}$, equalling 40.6 .

Significance weights of all quality criteria are given in Table 2. The total sum of significance rates makes 1 . The highest $Q_{\mathrm{H}}=0.155$ and the lowest $Q_{\mathrm{A}}=0.049$. The difference of significance indices equals 0.106 and the ratio -3.16 (Figure 1). A dotted horizontal straight line stands for the mean significance index of all quality criteria $Q_{i}=1: 10=0.1$.

Calculations performed according to the selected methodology showed the best agreement in the respondents' opinions where the significance of criterion $B\left(\sigma_{B}=1.43\right)$ was assessed, while the least 
agreement was demonstrated in the assessment of significance of criterion $F\left(\sigma_{\mathrm{F}}=2.91\right)$.

Analysis of the processed questionnaire data proved that among the total number of 10 quality criteria of rest areas and stopping places the most valued quality criteria included safety, convenience (infrastructure layout) and quality of the supplied services.

\section{Optimisation of rest area layout and evaluation of results}

The task of finding the best (the most optimal) solution among numerous potential (feasible) solutions is called the task of optimisation (Kalanta, 2007). A full coverage minimisation task was solved by using the application of subroutine "intlinprog" of software package "Matlab" with a reference.

The major part of documents and recommendations in Lithuania is prepared based on standard documents and expertise of Germany. The German normative standard states that the distance of minimum $15 \mathrm{~km}$ and maximum $25 \mathrm{~km}$ between the rest areas shall be ensured (Forschungsgesellschaft für Straßen- und Verkehrswesen, 2011). A list of rest areas along the main road A3 Vilnius-Minsk is given in Table 3.

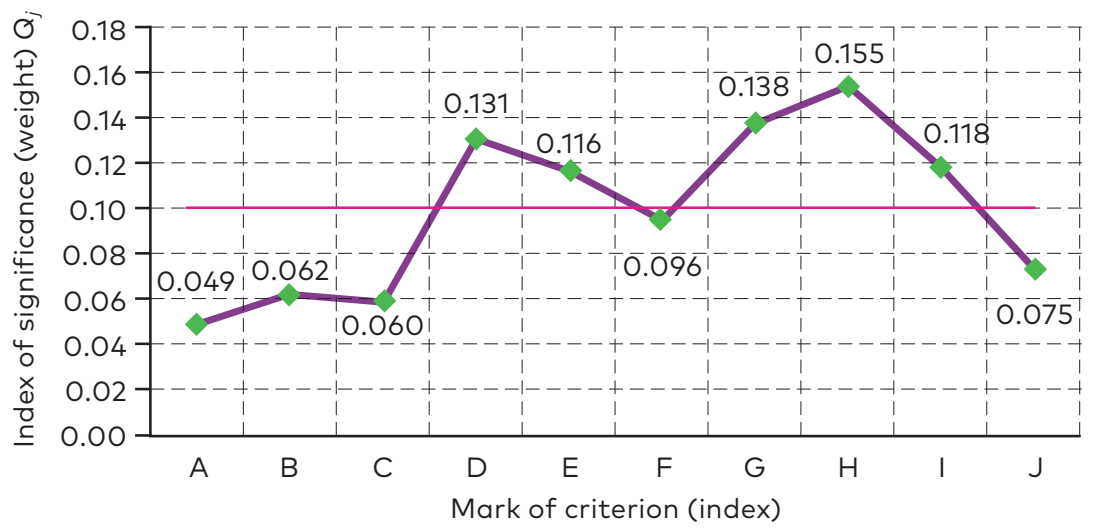

Figure 1. The values of the indices of significance (weight) $Q_{j}$ of quality criteria of the rest areas (compiled by the authors, 2019)
Justina Kolodinskaja, Lina Bertulienè

Layout of Rest Areas and Their Infrastructure Development in the South-Eastern Region of Lithuania 
Table 3. Data on the distance between rest areas on the main road A3 Vilnius-Minsk (compiled by the authors, 2019)

\begin{tabular}{ccccc}
\hline & Rest area No. & $\mathbf{1}$ & $\mathbf{2}$ & $\mathbf{3}$ \\
\hline $\mathbf{1}$ & Location, $\mathrm{km}$ & 0 & 8 & 33 \\
$\mathbf{2}$ & 0 & 0 & 8 & 33 \\
$\mathbf{3}$ & 8 & 8 & 0 & 25 \\
\hline
\end{tabular}

Based on the defined interval of distances, a list of rest areas is revised (Table 4).

Table 4. A list of rest areas on the main road A3 Vilnius-Minsk according to the set requirements (compiled by the authors, 2019)

\begin{tabular}{ccccc}
\hline & Rest area No. & $\mathbf{1}$ & $\mathbf{2}$ & $\mathbf{3}$ \\
\hline $\mathbf{1}$ & Location, $\mathrm{km}$ & 0 & 8 & 33 \\
$\mathbf{2}$ & 0 & 0 & - & - \\
$\mathbf{3}$ & 8 & - & 0 & 25 \\
\hline
\end{tabular}

Mathematical model of rest areas of the main road A3:

$$
\min f(x)=\sum_{j=1}^{3} x_{j}=x_{1}+x_{2}+x_{3}
$$

when

or

$$
\begin{aligned}
& x_{1} \geq 1 ; \\
& x_{2}+x_{3} \geq 1 \\
& x_{2}+x_{3} \geq 1 ; \\
& x_{j}=0
\end{aligned}
$$

$$
x_{j}=1, j=1, \ldots, 3 \text {. }
$$

The obtained solution of a full coverage minimisation task is $x_{1}^{*}=x_{3}^{*}=1$. Other variables are $x_{j}^{*}=0$, and the target function is $\min f\left(x^{*}\right)=2$. After minimisation of the task, it would be expedient to keep rest areas No. 1 and 3, while rest area No. 2 could be eliminated. Nevertheless, since rest area No. 2 is privately owned and equipped with the most essential structures and infrastructure elements, it is intended to keep it for the convenience of drivers and passengers.

The concept of the layout of roadside rest areas is illustrated in Figure 2 . 
Based on the results of optimisation task and the analysis of operational condition of rest areas, it was determined that 9 out of 27 rest zones in South-Eastern Lithuania should be eliminated and the additional rest area should be constructed on national road No. 103.

\section{Conclusions and recommendations}

Rest areas and stopping places shall be planned by dividing them into function zones: traffic zone, passenger and vehicle service facility zone, hygiene and sanitary facility zone and green plantation zone. A proper layout of rest areas results in a lower number of injury and fatal accidents since the drivers can take at least short stops and rest from continuous driving.

The surveyed rest areas on the five main transit roads in the southeastern region of Lithuania mostly lack proper infrastructure: WCs with water supply installed, area fencing, illumination, separation of vehicle parking lots, parking lots adjusted for the handicapped and rest zones equipped with the basic facilities.

It would be expedient for the south-eastern region of Lithuania, if nine rest areas were eliminated and 18 rest areas were kept and an

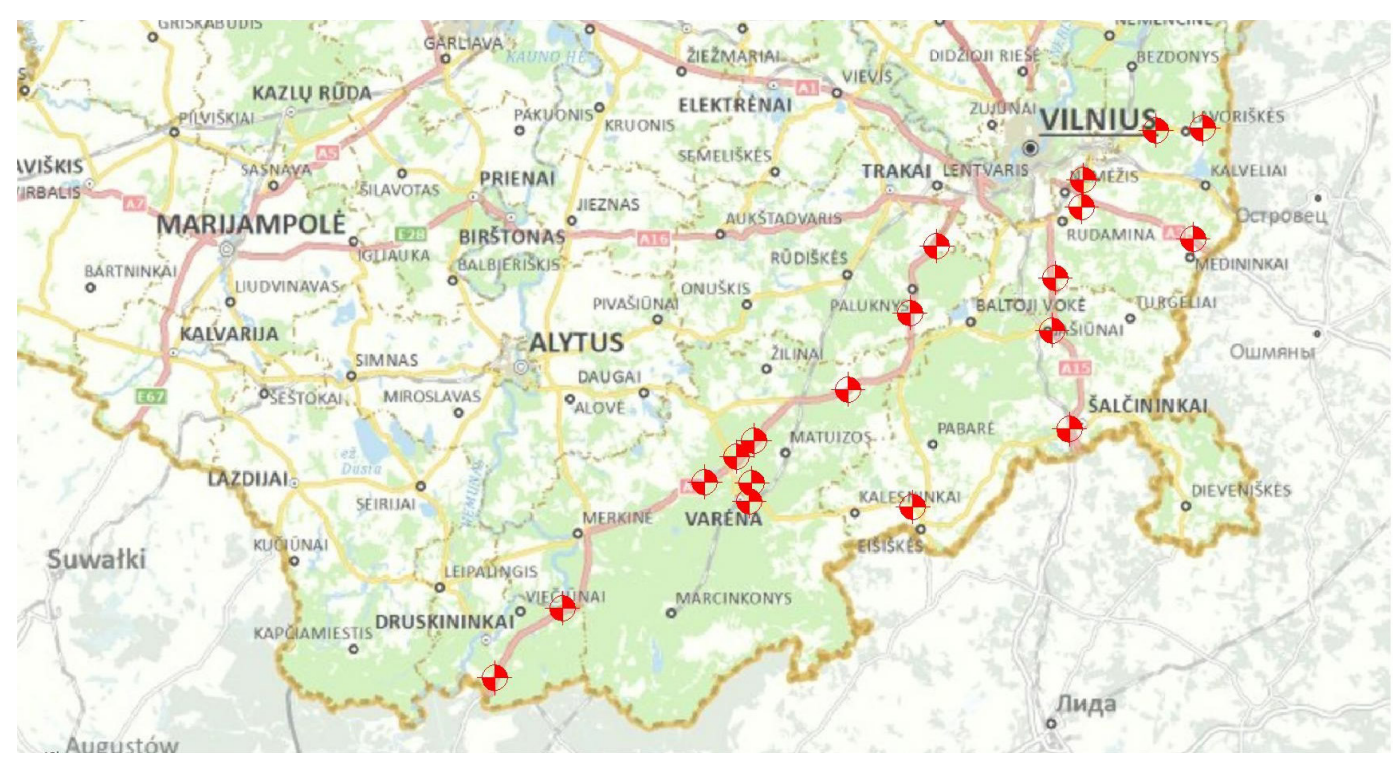

Figure 2. An alternative for the layout of rest areas in South-Eastern

Lithuania (compiled by the authors, 2019) 
additional rest area was planned on the border section of national road No. 103. Most of the existing rest areas should be upgraded or modernised via development of infrastructure, provision of minimum requirements and improvement of quality. Elimination of excessive rest areas would enable more efficient allocation of funds for the maintenance of other rest areas for the sake of improvement of their condition.

The interview results showed that the users of rest areas gave a high importance to not only the rest area safety $(A=8.3)$ but also convenience $(C=7.7)$. Thus, when upgrading rest areas it is necessary to consider their re-planning and when constructing new rest areas their division into function zones should be considered.

With due consideration given to the significance of the main criteria, optimisation method results and expertise of foreign countries, documents regulating the design of rest areas of Lithuania should be duly amended by including the necessary and functional infrastructure to ensure safety of the rest area users and the principle of rest area layout in terms of their type (50-60 km distance between the rest areas with service infrastructure; $15-20 \mathrm{~km}$ between the rest areas with service infrastructure and those without service infrastructure); proper positioning of road information/service signs: at a distance of $10 \mathrm{~km}$ to the area the type of rest area is to be indicated; at a distance of $2 \mathrm{~km}-$ type of the rest area and distance to another rest area is to be stated; at a distance of $1 \mathrm{~km}$ - an approaching rest area is to be indicated.

Rest areas with the infrastructure of services on Lithuanian roads remain topical, and their rapid development should be undertaken.

\section{REFERENCES}

Campbell, S. (2014). The economic evaluation of heavy vehicle rest areas-a new technique? Road \& Transport Research: A Journal of Australian and New Zealand Research and Practice, 23(1), 69.

Commission of the European Communities. (2009). Communication From the Commission to the European Parliament, The Council, the European Economic and Social Committee and the Committee of the Regions Concerning the EU Strategy for the Baltic Sea Region. Brussels. (2009). 11 p. Retrieved from: https://ec.europa.eu/regional_policy/sources/docoffic/ official/communic/baltic/com_baltic_en.pdf

Concept of traffic safety improvement in Latvia - Lithuania cross border region. (2013). Design guidelines for minor roadside rest area. Retrieved from: http://www.roadcomfort.eu

Forschungsgesellschaft für Straßen- und Verkehrswesen. (2011). Empfehlungen für Rastanlagen an Straßen ERS R2. Ausgabe. 62 p. 
Gates, T. J., Savolainen, P. T., Datta, T. K., \& Todd, R. G. (2013). Economic Assessment of Public Rest Areas and Traveler Information Centers on Limited-Access Freeways. Transportation Research Record: Journal of the Transportation Research Board, 2346(1), 63-71. https://doi.org/10.3141/2346-08

Jung, S., Joo, S., \& Oh, C. (2017). Evaluating the effects of supplemental rest areas on freeway crashes caused by drowsy driving. Accident Analysis \& Prevention, 99, 356-363. https://doi.org/10.1016/j.aap.2016.12.021

Kalanta, S. (2007). Taikomosios optimizacijos pagrindai [Basics of the applied optimisation]. Vilnius: Technika. 480 p. https://doi.org/10.3846/924-S

Lithuanian Road Administration under the Ministry of Transport and Communications (2019). Road maintenance guidebook. Part I. Norms of regular maintenance of roads. KPV PN-19. (2019).

Lithuanian roads information system LAKIS. (2019). Retrieved from: https://gis.eismoinfo.lt/lakis/

McArthur, A., Kay, J., Savolainen, P. T., \& Gates, T. J. (2013). Effects of Public Rest Areas on Fatigue-Related Crashes. Transportation Research Record: Journal of the Transportation Research Board, 2386(1), 16-25. https://doi.org/10.3141/2386-03

Ministry of Environment of the Republic of Lithuania. (2008). Road Technical Regulation KTR 1.01:2008 Motorways. (2008). 39 p.

Ministry of Transportation and Infrastructure. (2016). Highway rest area survey report. Truck stop services in B.C. Market research. Retrieved from: https://www2.gov.bc.ca/assets/gov/driving-and-transportation/ reports-and-reference/reports-and-studies/planning-strategy-economy/ highway-rest-area-survey-report.pdf

Pérez-Acebo, H., \& Romo-Martín, A. (2019). Service and rest areas in toll motorways in Poland: study of distribution and facilities. Transport Problems, 14(2), 155-164. https://doi.org/10.20858/tp.2019.14.2.14

Podviezko, V. \& Podviezko, A. (2014). Kriterijų reikšmingumo nustatymo metodai [Methods for determination of criteria significance]. Lietuvos matematikos rinkinys [Lithuanian mathematics collection], 55, 111-116. https://doi.org/10.15388/LMR.B.2014.21

Romo-Martín, A., \& Pérez-Acebo, H. (2018). Analysis of the Location of Service and Rest Areas and their facilities in Spanish paying motorways. Transportation Research Procedia, 33, 4-11. https://doi.org/10.1016/j.trpro.2018.10.069

Sivilevičius, H. (2011) Application of expert evaluation method to determine the importance of operating asphalt mixing plant quality criteria and rank correlation. The Baltic Journal of Road and Bridge Engineering, 6(1), 48-58. ISSN 1822-427X. https://doi.org/10.3846/bjrbe.2011.07
Justina Kolodinskaja,

Lina Bertulienè

Layout of Rest

Areas and Their

Infrastructure

Development in

the South-Eastern

Region of Lithuania 